\title{
Destructive Dural Ectasia of Dorsal and Lumbar Spine with Cauda Equina Syndrome in a Patient with Ankylosing Spondylitis
}

\author{
Marijke Van Hoydonck, Kurt de Vlam, Rene Westhovens, Frank P. Luyten and Rik J. Lories*
}

Division of Rheumatology, University Hospitals Leuven, Herestraat 49, B-3000, Leuven, Belgium

\begin{abstract}
We present a patient with longstanding ankylosing spondylitis complicated with cauda equina syndrome. The patient suffered from increasing pain in the leg with reduced sensitivity and extremely cold feet associated with incontinence. Diagnostic workup revealed dural ectasia, arachnoiditis and a spinal inflammatory mass leading to extensive vertebral bone destruction. Of interest, this was not only found in the lumbar spine region (which is typical in cases of cauda equina syndrome associated with ankylosing spondylitis) but also in the lower cervical spine (C7) and upper dorsal spine. Moreover, the bone destructive phenotype of this complication of long-standing AS contrasts with the usual characteristics of new bone formation and ankylosis. As initial treatment with anti-inflammatory drugs was not sufficiently successful, infliximab therapy was started which resulted in manifest clinical improvement as chronic pain, incontinence and laboratory signs of inflammation progressively disappeared.
\end{abstract}

Keywords: Ankylosing spondylitis, cauda equina syndrome, bone destruction, anti-TNF.

\section{INTRODUCTION}

Dural ectasia and arachnoiditis, sometimes leading to cauda equina syndrome, are rare complications of ankylosing spondylitis and can be a diagnostic and therapeutic challenge [1-5]. Here, we present a patient in whom dural ectasia is accompanied by remarkable bone destruction both in the cervical, dorsal and lumbar spine.

\section{CASE}

A 73-year-old male was referred to the outpatient spondyloarthritis clinic by his general practitioner. He was diagnosed with ankylosing spondylitis in his early twenties and had been treated for decades with phenylbutazone and sulfasalazine. For the last 10 years he had not been under the specific care of a rheumatologist.

His medical history further included two pneumonias (in 1984 and 1997), surgery for inguinal herniation and benign prostate hypertrophy. He was also treated for hypertension (bisoprolol, hydrochlorothiazide and lisinopril) and hypercholesterolemia (simvastatine). One year before this referral, treatment with phenylbutazone was stopped as the product was no longer commercially available.

He suffered from increasing pain in the left leg and foot over the last 6 months, and also mentioned loss of sensitivity in the leg and extremely cold feet. Pain increased in recumbent position, in particular at night, and disappeared upon walking or biking. On further questioning the patient indicated urinary and fecal incontinence. The urinary incontinence was previously attributed to benign prostate hypertrophy, for which he underwent a transurethral procedure in 2006. However, this procedure did not result in significant subjective improvement.

*Address correspondence to this author at the Division of Rheumatology, University Hospitals Leuven, Herestraat 49, B-3000, Leuven, Belgium; Tel: +32-16-342541; Fax: +32-16-342543; E-mail: Rik.Lories@uz.kuleuven.be
Clinical examination revealed loss of axial mobility with a modified Schöber index of $0.5 \mathrm{~cm}$, a lumbar lateroflexion of $2.0 \mathrm{~cm}$, tragus to wall distance of $28.0 \mathrm{~cm}$ and a cervical rotation of $10^{\circ}$. We also noted extremely cold feet with reduced sensibility in the left foot, normal arterial pulsations of the arteria femoralis and arteria tibialis posterior but bilateral absence of pulsations in the arteria dorsalis pedis.

Biochemistry showed C-reactive protein (CRP) levels of $18.4 \mathrm{mg} / \mathrm{dl}$ (reference value $<5 \mathrm{mg} / \mathrm{dl}$ ) and an Erythrocyte Sedimentation Rate (ESR) of $21 \mathrm{~mm} /$ hour (reference value < $10 \mathrm{~mm} / \mathrm{h}$ ). Further vascular investigation included an angiography by nuclear magnetic resonance imaging (MRI) that showed normal aorto-iliacal, femoral and popliteal vessels. X-ray of the lower back region showed bilateral grade IV sacroiliitis and a bamboo spine (Fig. 1a). The axis of the lumbar spine was shifted to the left. As lumbar stenosis was suspected, computed tomography (CT) of the lumbar spine and electromyography (EMG) were performed. CT revealed dural ectasia with osteolysis of the arcus posterior from lumbar vertebra 1 to 4 and extending into the spinal canal (Fig. 1b, c). EMG confirmed bilateral denervation in S1 and unilateral re-innervation of L4-S1, and L5-S1 on the left and right side respectively. MRI of the lumbar spine region showed a bamboo spine with active inflammation in the vertebrae (Fig. 1d). Dural ectasia was confirmed and sequelae of arachnoiditis were suspected, in particular the existence of a mass in the cauda equina in continuity with the dura (Fig. 1d).

During the diagnostic work-up, the patient was admitted to the hospital because of bilateral community acquired pneumonia, successfully treated with intravenous antibiotics. Rehabilitation with physiotherapy during the hospital stay improved some of the symptoms and treatment with phenylbutazone on demand was reinstalled with good results. The general condition of the patient further suggested a conservative approach. Out patient visits suggested that his status remained reasonably well. 

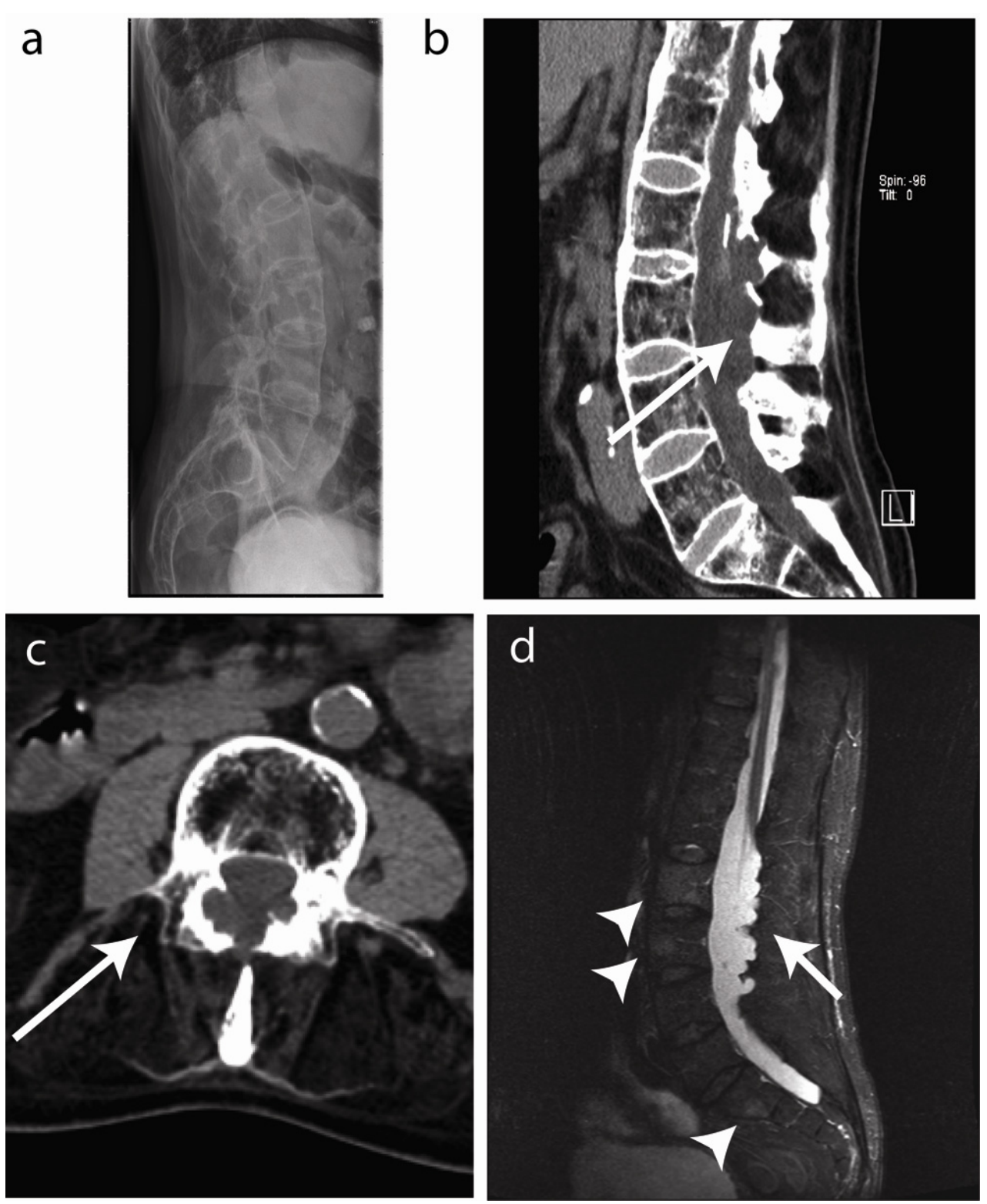

Fig. (1). Imaging of the lumbar spine. (a) Longstanding disease resulted in a characteristic bamboo spine with ankylosis and osteoporosis. (b) CT imaging revealed dural ectasia with osteolysis of the arcus posterior from lumbar vertebra 1 to 4 (L1-4) and extending into the spine channel (arrow) on a sagittal view. (c) Transverse CT section showing arcus destruction in L3 (arrow). (d) Short TI Inversion Recovery (STIR) MRI images show inflammation in the vertebral bodies (arrowheads) and arachnoiditis with a contrast capturing mass in the cauda equine in continuity with the dura (arrow).

A few months after his stay at our ward, the patient fell at home and was hospitalized elsewhere. His major complaint consisted in increasing dorsal pain for which he underwent an MRI of the dorsal spine. The MRI described an image of bone remodeling in $\mathrm{C} 7, \mathrm{D} 3, \mathrm{D} 4$ and $\mathrm{D} 5$ and a soft paravertebral tissue mass on the right side of D3 (Fig. 2a). After transfer to our clinic, CT showed osteolytic lesions in D3, D4 and D5 (corpus, processus spinosus and processus transversus) with diffuse cortical damage and destruction of the posterior wall of the vertebrae (Fig. 2b-d). The presence of a prevertebral mass on the right side $(3.3 \times 1.7 \times 2.7 \mathrm{~cm})$ was confirmed (Fig. 2c, d). We thus diagnosed a process in the dorsal spine largely similar to that seen earlier in the lumbar spine with active arachnoiditis, intraspinal cysts and bone erosion.
Further deterioration of the general status of this patient occurred. Since we found evidence for active inflammation of the spine (on MRI and biochemistry) we decided to start treatment with infliximab at a dosing scheme of $5 \mathrm{mg} / \mathrm{kg}$ (w0, w2, w6). BASDAI at onset was 4.9/10. After 3 infusions it lowered to 3.1/10. Inflammation in the blood disappeared and there was a noticable clinical improvement with complete recuperation of the faecal incontinence and the disappearance of back pain. The loss of sensitivity in the left leg however persisted.

\section{DISCUSSION}

Neurological manifestations of AS are rare and occur in approximately $2.1 \%$ of patients [2, 3]. Cauda equina syndrome has been described as a complication of long- 

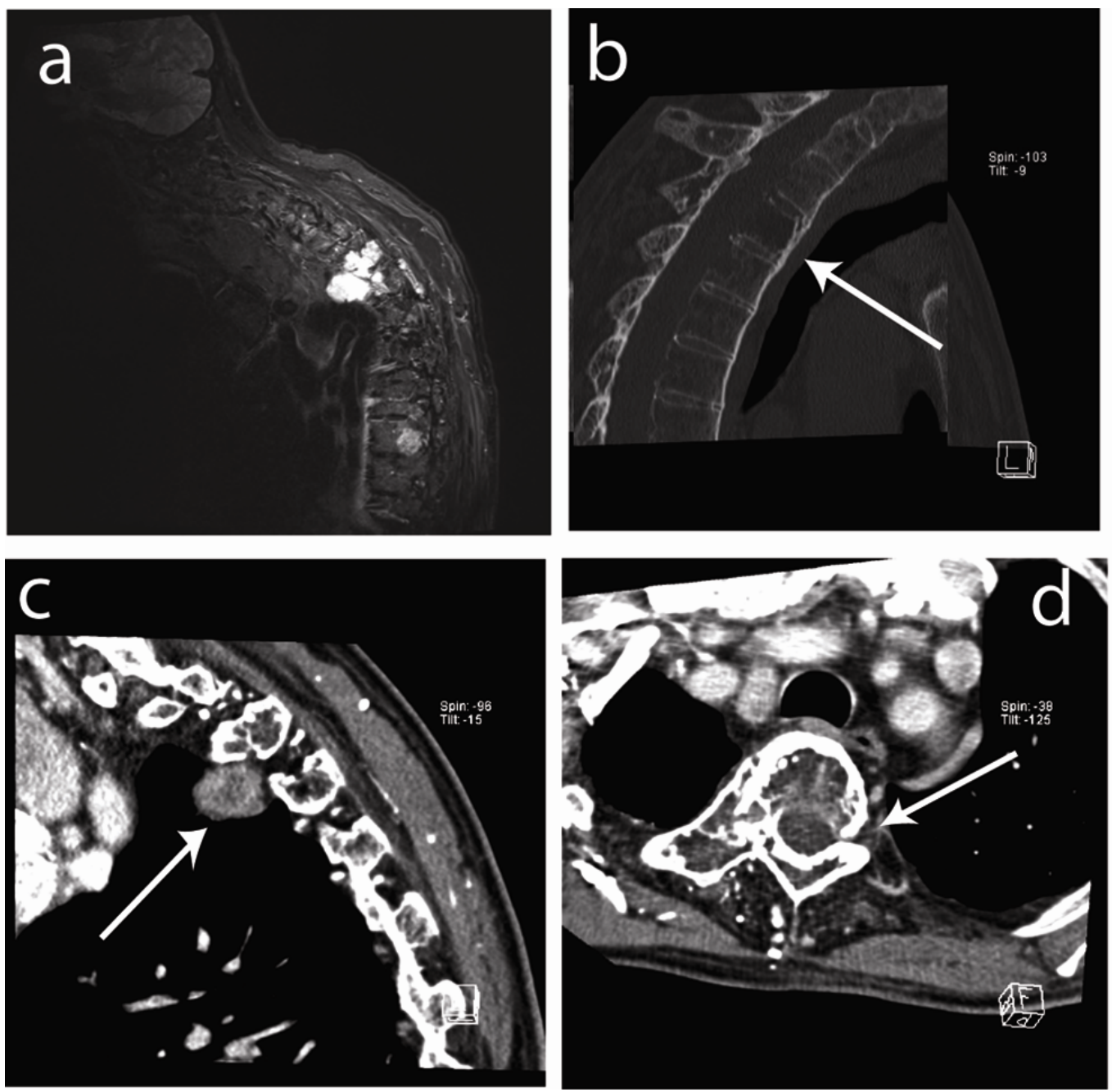

Fig. (2). Imaging of the cervical and dorsal spine. (a) Soft tissue prevertebral mass on the right side of dorsal vertebra 3 (D3) visualized by STIR MRI. (b) Sagital CT image showing osteolytic lesions (arrow) in vertebrae D3, D4 and D5 (corpus, processus spinosus and transversus) with diffuse cortical involvement and destruction of the posterior wall. (c) Sagital CT image showing the prevertebral mass on the right side $(3.3 \times 1.7 \times 2.7 \mathrm{~cm})$ (arrow). (d) Transverse CT image showing osteolytic destruction (arrow).

standing ankylosing spondylitis. At the time of diagnosis most patients do not show any inflammation in the blood, or on MRI [2-9], but in the case presented here signs of active inflammation were detected.

Cauda equina syndrome (CES) is considered a serious neurological condition with progressive loss of function of the neurologic elements of the spinal canal below the termination of the spinal cord. Common causes of CES are prolaps of an intervertebral disc, metastatic disease, direct trauma from lumbar puncture and spinal anesthesia. Also penetrating wounds, spinal stenosis due to a degenerative process, development defects and inflammatory conditions such as Paget's disease and ankylosing spondylitis can cause CES [4].

The pathogenesis of CES remains unclear. Possible pathogenic mechanisms include inflammation and arachnoiditis (with subsequent fibrosis and formation of dural ectasia), mechanical stretching and compression of the nerve roots (by dural ectasia or arachnoid cysts, or secondary to an arterial pulse wave), reduced compliance of the caudal sac and a demyelination due to radiotherapy or ischaemia [210].

In this case chronic arachnoiditis with formation of dural ectasia and subsequent loss of meningeal elasticity is a likely mechanism for the CES. Furthermore, arachnoiditis does not only affect the lower spine, but is also present in the upper regions. MRI of the cervical and dorsal spine indicates active arachnoiditis. Dural ectasia and osteolysis at this level were not as severe as in the lumbar spine, suggesting that these findings might represent an earlier phase in the disease process.

This is the first case where dural ectasia and osteolysis are described in lower cervical spine (C7), upper dorsal and lumbar spine. In the literature, non-lumbar localization of dural ectasia has been seen in the cervical and thoracic region in patients with neurofibromatosis [11] but not yet in ankylosing spondylitis.

The osteolytic, bone-destructive changes are remarkable as ankylosing spondylitis is typically associated with bone formation rather than destruction [12]. The link between arachnoiditis and bone destruction of the posterior elements 
further supports an inflammatory stimulus for bone destruction in particular a role for osteoclasts [13].

In conclusion, dura and cauda equina involvement are rare complications of long-standing ankylosing spondylitis. In this patient inflammation apparently resulted in a bone destructive mass in both lower cervical (C7), upper dorsal and lumbar spine, which is a very unusual phenotype for ankylosing spondylitis. If neurologic deficits occur in patients with long-standing AS a complete neurologic workup, as well as MRI of the spine are indicated.

\section{REFERENCES}

[1] Westhovens R, Verstraeten A, Knockaert D, et al. Cauda equina syndrome complicating ankylosing spondylitis: role of computed tomography and magnetic resonance imaging. Clin Rheumatol 1994; 13: 284-8.

[2] Dinichert A, Cornelius JF, Lot G. Lumboperitoneal shunt for treatment of dural ectasia in ankylosing spondylitis. J Clin Neurosci 2008; 15: 1179-82.

[3] Ahn NU, Ahn UM, Nallamshetty L, et al. Cauda equina syndrome in ankylosing spondylitis (the CES-AS syndrome): meta-analysis of outcomes after medical and surgical treatments. J Spinal Disord $2001 ; 14: 427-33$

[4] Mitchell MJ, Sartoris DJ, Moody D, Resnick D. Cauda equina syndrome complicating ankylosing spondylitis. Radiology 1990; 175: $521-5$
[5] Cornec D, Devauchelle PV, Joulin SJ, Saraux A. Dramatic efficacy of infliximab in cauda equina syndrome complicating ankylosing spondylitis. Arthritis Rheum 2009; 60: 1657-60.

[6] Arslanoglu A, Aygun N. Magnetic resonance imaging of cauda equina syndrome in long-standing ankylosing spondylitis. Australas Radiol 2007; 51: 375-7.

[7] Lan HH, Chen DY, Chen CC, Lan JL, Hsieh CW. Combination of transverse myelitis and arachnoiditis in cauda equina syndrome of long-standing ankylosing spondylitis: MRI features and its role in clinical management. Clin Rheumatol 2007; 26: 1963-7.

[8] Shaw PJ, Allcutt DA, Bates D, Crawford PJ. Cauda equina syndrome associated with multiple lumbar arachnoid cysts in ankylosing spondylitis: improvement following surgical therapy. J Neurol Neurosurg Psychiatry 1990; 53: 1076-9.

[9] Rubenstein DJ, Alvarez O, Ghelman B, Marchisello P. Cauda equina syndrome complicating ankylosing spondylitis: MR features. J Comput Assist Tomogr 1989; 13: 511-13.

[10] Kotil K, Yavasca P. Lumbar radiculopathy in ankylosing spondylitis with dural ectasia. J Clin Neurosci 2007; 14: 981-3.

[11] Garcia-Estevez DA, Arce-Perez M. [Dural ectasia in the cervical spine and neurofibromatosis type 1]. Rev Neurol 2009; 48: 51.

[12] Lories RJ, Luyten FP, De Vlam K. Progress in spondylarthritis. Mechanisms of new bone formation in spondyloarthritis. Arthritis Res Ther 2009; 11: 221.

[13] Schett G. Osteoimmunology in rheumatic diseases. Arthritis Res Ther 2009; 11: 210.

(C) Van Hoydonck et al.; Licensee Bentham Open.

This is an open access article licensed under the terms of the Creative Commons Attribution Non-Commercial License (http://creativecommons.org/licenses/by-nc/ $3.0 /$ ) which permits unrestricted, non-commercial use, distribution and reproduction in any medium, provided the work is properly cited. 